\title{
O REGISTRO DE NASCIMENTO E SUA IMPORTÂNCIA EM PLANEJAMENTO MATERNO-INFANTIL
}

\author{
Maria Stella LEVY (2) \\ Arnaldo A. SIQUEIRA (1) \\ Maria Helena SILVEIRA (1) \\ Susana P. TASCHNER (2)
}

LEvy, M. S. et al. - O registro de nascimento e sua importância em planejamento materno-infantil. Rev. Saúde puibl., S. Paulo, 5:41-6, 1971.

RESUMO - Foi estimada a proporção de nascimentos registrados conforme o artigo 63 do decreto n. 4.857 de 9 de novembro de 1939 - Lei dos Registros Públicos que obirga o registro de nascimento "no cartório do lugar em que tiver ocorrido o parto, no prazo de 15 dias após o nascimento", ou "na falta ou impedimento do pai", até 60 dias após o nascimento. No distrito de São Paulo, por "lugar onde ocorreu o parto", entende-se cada um dos 48 subdistritos em que o mesmo se subdivide. Com base em amostras colhidas em maternidades, foram estimadas essas proporções, no ano base de 1969 .

UnITERMos - Registro de nascimentos*; Planejamento de saúde maternoinfantil *; Estatística vital *; Demografia.

\section{INTRODUCAO}

0 problema do sub-registro de nascimento, e de formas não adequadas de registro, é de importância capital para trabalhos de planejamento de saúde materno-infantil. A existência de grande número de nascidos vivos não registrados deforma enormemente as estatísticas vitais nas quais êsses trabalhos se baseiam, conduzindo todo um esfôrço de previsão a resultados de confiança duvidosa. Daí a importância de um estudo no gênero do que foi proposto. Cabe ainda, entretanto, deixar claro aqui, que essa avaliação não esgota o assunto: é apenas passo inicial, uma vez que se estudam sòmente nascimentos ocorridos em maternidades e registrados no lugar e prazo legais.

Foram selecionadas maternidades consideradas representativas de:

$$
\begin{aligned}
& \text { A - classe "alta" } \\
& \text { B - classe "média" } \\
& \text { C - classe "baixa" }
\end{aligned}
$$

Além da diferenciação por classe social, procurou-se também, testar a eficácia da orientação dada à parturiente.

Recebido para publicação em 15-3-1971.

(1) Do Departamento de Epidemiologia da Faculdade de Saúde Pública da USP - Av. Dr. Arnaldo, 715 - São Paulo, SP - Brasil.

(2) Do Centro de Estudos de Dinâmica Populacional (CEDIP) da Faculdade de Saúde Pública da USP - Av. Dr. Arnaldo, 715 - São Paulo, SP - Brasil. 
LEVY, M. S. et al. - O registro de nascimento e sua importáncia em planejamento materno-infantil. Rev. Saúde públ., S. Paulo, 5:41-6, 1971.

Essa orientação consiste em um informativo entregue à mãe, quando esta dá entrada na maternidade por ocasião do parto, dizendo da obrigatoriedade do registro e indicando o local e prazo para ser feito.

Verificou-se que as maternidades que atendem à classe "alta" (A) sempre dão essa orientação. Assim, não nos foi possível trabalhar com grupo de contrôle nessa classe. Utilizou-se grupo contrôle apenas para a classe $\mathrm{C}$.

Assim sendo, as hipóteses que nortearam o trabalho foram de dois tipos:

1. haveria associação direta positiva entre classe social mais alta e cumprimento da lei;

2. haveria associação direta positiva entre orientação e cumprimento da lei, na classe $C$.

\section{MATERIAL E METODOS}

A população fixada para estudo foi a dos nascidos vivos do mês de novembro de 1969, nas seguintes maternidades:

classe A: Maternidade de São Paulo, seção de particulares;

classe B: Casa de Saúde D. Pedro II (considerou-se como classe "média" pacientes do INPS e demais institutos de previdência social);

classe C: Maternidade de São Paulo, seção de indigentes (com orientação;

Amparo Maternal (sem orientação).

\section{1 -Processo de amostragem}

A unidade amostral estabelecida foi $o$ nascido vivo e o processo de amostragem utilizado foi diverso nas diferentes fases da pesquisa.

a) Para a escolha das maternidades representativas de cada um dos estratos sociais, contou-se com a colaboração de pesquisadores da Investigação Interamericana de Mortalidade na Infância ${ }^{(1)}$. .Assim, a escolha das maternidades foi intencional e não probabilística.

b) Para o sorteio dos nascidos vivos utilizou-se amostragem casual sistemática, com início dado pela tabela de número casuais e intervalo adequado para o tamanho da amostra.

\section{2 - Cálculo do tamanho da amostra}

0 tamanho da amostra foi função:

a) do número médio mensal de partos (estimados a partir de 1968);

b) da proporção esperada de registrados em cada maternidade $(\stackrel{\wedge}{\mathrm{P}})$.

Essa proporção foi proposta pelos membros da Investigação já mencionada e difere para cada maternidade.

A estatística utilizada para o cálculo do tamanho da amostra em tôdas as maternidades foi $\operatorname{Pr}\{|\mathrm{P}-\mathrm{p}|>0,10\}=10 \%$ ou seja: a probabilidade de que a diferença entre os valôres da verdadeira proporçãa de registrados e o valor encontrado na amostra seja maior do que $10 \%$, é de $10 \%$.

Trabalhou-se então com variância $\pi \mathrm{p}^{2}=37,1856 \times 10^{-4}$, e o tamanho da amostra (n), foi dado por

$$
\mathrm{n}=\frac{\mathrm{n}_{\mathrm{o}}}{1-\frac{\mathrm{n}_{0}-1}{N}} \quad \mathrm{n}_{0}=\frac{\stackrel{\hat{P}}{\mathrm{P}}(1-\hat{\mathrm{P}})}{\pi \mathbf{p}^{2}}
$$

sendo

$$
\mathrm{N}=\text { tamanho da população }
$$

(1) Investigação dirigida pelo Dr. Ruy Laurenti, do Departamento de Epidemiologia da Faculdade de Saúde Pública da USP, que vem sendo realizada desde 1968, fínanciada pela OMS. 
LEVY, M. S. et al. - o registro de nascimento e sua importância em planejamento materno-infantil. Rev. Saúde públ., S. Paulo, 5:41-6, 1971.

TABEL 1

Número médio mensal de partos, proporção esperada de registros $(\hat{\mathbf{P}})$ e tamanho da amostra (n), por maternidade.

\begin{tabular}{l|c|c|c}
\hline \multicolumn{1}{c|}{ Maternidades } & $\begin{array}{c}\text { Partos médios } \\
\text { mensais (n.v.) }\end{array}$ & $\begin{array}{c}\text { Proporção es- } \\
\text { perada de re- } \\
\text { gistros (P) }\end{array}$ & $\begin{array}{c}\text { Tamanho da } \\
\text { amostra (n) }\end{array}$ \\
\hline Maternidade de S. Paulo (particular) & 398 & $70 \%$ & 50 \\
Casa de Saúde Dom Pedro II & 150 & $70 \%$ & $40\left(^{*}\right)$ \\
Maternidade de S. Paulo (Indigentes) & 335 & $40 \%$ & 54 \\
Amparo Maternal & 417 & $10 \%$ & 23 \\
\hline
\end{tabular}

(*) Na amostra só apareceram 39 casos, pois no mês de novembro de 1969, o número de partos de nascidos vivos foi menor do que a estimativa mensal.

$\mathrm{n}_{\mathrm{o}}=$ tamanho da amostra se a população fôsse infinita

$\stackrel{\hat{P}}{\mathrm{P}}=$ proporção esperada de registrados em cada maternidade

Os resultados obtidos constam da Tabela 1 .

\section{3 - Método para coleta de dados}

Coletou-se o material necessário através do arquivo médico de cada maternidade. Foram prèviamente excluídos das fichas do mês de novembro de 1969, já ordenadas por data de nascimento, tôdas as de nascidos mortos.

Procedeu-se a uma amostragem sistemática, com início casual e intervalo inversamente proporcional ao tamanho da amostra (n) e diretamente proporcional ao número médio de partos mensais, anotando-se o nome da mãe, sexo do recém nascido e data do nascimento.

Como da súmula dos hospitais não consta o nome da criança, não houve possibilidade de ser usado o índice do Livro de Registros de Nascimentos.

De posse da lista sorteada, com as devidas informaçōes, foi-se ao cartório do Registro Civil do subdistrito de cada maternidade e percorreu-se o Livro de Re- gistros de Nascimentos - a partir de $10^{\circ}$ de novembro de 1969 a 31 de janeiro de 1970 - buscando encontrar, dentre os nascimentos ocorridos nas citadas maternidades, os que correspondessem aos selecionados na amostra.

\section{RESULTADOS}

Os resultados encontrados estão dispostos na Tabela 2.

Esses resultados indicam o seguinte:

a) As maternidades classes A e B (São Paulo, particular, e D. Pedro II, respectivamente) apresentam proporção de registros que não diferem significantemente de $50 \%$ (teste monocaudal, com nível de significância de 5\%);

b) As proporçōes encontradas nas duas maternidades classe $\mathrm{C}$ são significantemente menores do que $50 \%(\alpha=5 \%)$;

c) Comparando as percentagens encontradas entre as duas maternidades $\mathbf{A}$ e $B$, verifica-se que não diferem significantemente a um nivel de 5\% (teste: método de contraste de Goodman ${ }^{1}$ ) ;

d) Não houve diferença significante (teste de Goodman, $\alpha=5 \%$ ) entre as 
LEVY, M. S. et al. - o registro de nascimento e sua importância em planejamento materno-infantll. Rev. Saude públ., S. Paulo, 5:41-6, 1971.

T A B EL A 2

Proporção de casos registrados no prazo e local exigidos por lei, por maternidade

\begin{tabular}{l|l|l|l|c}
\hline & Registrados & Não & Total & $\begin{array}{c}\text { Tamanho } \\
\text { da amos- } \\
\text { tra (n) }\end{array}$ \\
Maternidades & & & & \\
\hline Maternidade de São Paulo (particular) & 48,36 & 51,64 & 100,00 & 50 \\
Casa de Saúde Dom Pedro II & 46,15 & 53,85 & 100,00 & 39 \\
Maternidade de São Paulo (indigentes) & 13,48 & 86,52 & 100,00 & 54 \\
Amparo Maternal & 13,04 & 86,96 & 100,00 & 23 \\
\hline
\end{tabular}

proporções de registros dentro do prazo e no lugar devido nas duas maternidades classe C. Assim pode-se supor que, nesse grupo, é de pouca valia a orientação dada para o registro.

e) Foram significantes as diferenças de cada uma das duas primeiras maternidades (A e B) com cada uma das últimas $(C)$.

f) Convém ainda notar, que o cartório do Registro Civil da área da Casa de Saúde $D$. Pedro II envia três vêzes por semana um oficial de registro àquela Maternidade. Isso, é claro, deve ter viciado a conclusão para maternidade classe $B$.

\section{DISCUSS X}

Pelos resultados obtidos verificou-se que na melhor das hipóteses o registro em tempo e local legais, chega próximo aos 50\%. O que acontece com os outros registros? Pode ocorrer uma das quatro hipóteses:

1. - o nascimento é registrado dentro do prazo legal, mas não no cartório estipulado por lei;

2. - o nascimento é registrado no cartório da área da maternidade, porém fora do prazo legal;
3. - o nascimento é registrado fora do prazo legal e em cartório que não o da área;

4." - o nascimento não é registrado em lugar nenhum. Sabe-se nêste caso, que a estimativa da percentagem de subregistro no Município de São Paulo, no prazo de 45 dias, é de $3,2 \%{ }^{2}$.

Os cartórios só podem registrar nascimentos ocorridos na sua área de ação. Ao ser registrado um nascimento que não obedeça a essa prescrição, o encarregado, visando a não deixar de receber as custas provenientes daquele registro, anota como local de nascimento "em residência" ou simplesmente "neste subdistrito", sem maiores especificações.

Quais as conseqüências e implicações decorrentes dêsse fato?

a) Como os mapas do Departamento Estadual de Estatística são feitos a partir dos dados dos cartórios, aumentaria a proporção de partos domiciliares. De acôrdo com YunEs ${ }^{3}$, baseado em informações do Departamento Estadual de Estatística, $51,92 \%$ dos partos do Município de São Paulo são domiciliares. Através dos dados obtidos pela Investigação Interamericana de Mortalidade na Infância, na amostra contrôle de 306 nascidos vivos menores de um ano e residentes no distrito de São Paulo, encontrou-se a propor- 
LEVY, M. S. et al. - o registro de nascimento e sua importância em planejamento materno-infantil. Rev. Saúde públ., S. Paulo, 5:41-6, 1971.

ção de $7,58 \%$ de partos domiciliares. Essa amostra contrôle foi tirada de julho de 1968 a junho de 1970.

b) Pode acontecer também que bairros essencialmente industriais, tenham uma alta percentagem de nascimentos (devido à localização do trabalho dos pais), que deveriam ter sido registrados em outros subdistritos.

c) A obrigatoriedade do registro se dar "no lugar onde ocorreu o nascimento" concorre para que o maior índice de nascimentos se apresente nos bairros onde se concentra maior número de hospitais. Não existindo possibilidade de conhecer a distribuição territorial de nascimentos no Município, é extremamente difícil realizar com eficácia programas de saúde ou educação da infância ou da gestante. $\mathbf{O}$ conhecimento $\mathrm{da}$ distribuição de eventos vitais por subdistritos é imprescindível para melhor uso do espaço, localizando serviços de saúde onde a demanda é maior.

d) Os dados colhidos nêste estudo provêm do ano de 1969, portanto anteriores ao decreto 52425 de 25 de março de 1970, que entrou em vigor em $10^{\circ}$ de abril de 1970 e que fixa o preço para registro de nascimento.

Antes disso, era estimulada a procura de certos cartórios de bairros periféricos, que ofereciam preços mais convenientes:

e) Embora essa nova lei venha sanar êsse aspecto do problema, ela tabela o preço do registro com uma cópia em Cr $\$ 25,00^{(*)}$, quando feito no prazo, e em $\operatorname{Cr} \$ 37,00^{(* *)}$, quando fora do prazo legal.

Lembrando que nem mesmo a casa de Saúde D. Pedro II apresentou proporção de registrados no prazo e local devidos maior do que $50 \%$, nota-se que grande parte da população teria que pagar quan- tia relativamente elevada para registrar seus filhos. Isso evidentemente não estimula o cumprimento da lei.

Como o correto registro de eventos vitais é fator essencial a um planejamento adequado, para quase todos os serviços públicos e privados, seria de grande interêsse a gratuidade dêsses serviços, que passariam a ser encargo da coletividade.

f) Ainda resta ressaltar aqui que, embora tendo utilizado sòmente o mês de novembro de 1969 para êste estudo, nada faz supor que o referido mês se comporte de maneira diversa dos demais, quanto ao problema estudado.

\section{CONCLUSOES}

As afirmações feitas especialmente nos parágrafos "a", "c" e "e", da seção "Discussão", até certo ponto, são as que causam maiores dificuldades. Já foi discutida a importância da melhoria dos registros de eventos vitais, para equacionamento mais adequado dos problemas da população.

Assim, pode-se pensar em algumas sugestões:

a) Uma das maneiras de se diminuir o indice de sub-registros, seria a gratuidade do serviço.

b) Se o registro de nascimento fôsse feito no lugar de residência da mãe, poder-se-ia medir a natalidade por área. Esse é um ponto de importância capital para o conhecimento de aspectos demográficos por setores da capital, que facilitaria a implantação de equipamentos adequados em lugares prioritários.

Não se deve esquecer, entretanto, que qualquer uma das medidas propostas iria tornar possível, entre outras coisas, um

(*) Equivalente a $13,35 \%$ do salário minimo vigente na época (Cr\$ 187,20).

(**) Equivalente a $19,76 \%$ do salário minimo vigente na época (Cr\$ 187,20). 
LEVY, M. S. et al. - o registro de nascimento e sua importáncia em planejamento materno-infantil. Rev. Saúde públ., S. Paulo, 5:41-6, 1971.

melhor conhecimento da nossa realidade, para que a mobilização de recursos necessários para programas de saúde materno-infantil, fôsse planejado de tal forma que a população pudesse beneficiar-se de seus efeitos de forma integral.

LEVY, M. S. et al. - [Live-birth register and its importance to maternal and child care planning]. Rev. Saúde públ., S. Paulo, 5:41-6, 1971.

SUMMARY - With basic on a probabilistic sample of live births collected in maternities, an estimative of the proportion of live births registered was made. According to the Brazilian law, the register has to be done in an especific date and place, depending on the local area where the birth occurred. The year-base for this study was 1969.

UNITERMS - Birth certificates *; Maternal and child care planning *; Vital Statistics*; Demography.

\section{REFERENCIAS BIBLIOGRAFICAS}

1. GOODMAN, L. A. - Simultaneous confidence intervals for contrasts among multinomial populations. Ann. Math. Stat., 31: 716-25, 1964.

2. MILANESI, M. L. \& SILVA, E. P. C. Sub-registro de nascimentos no distrito de São Paulo. Rev. Saúde públ., S. Paulo, 2: 23-8, 1968.

3. YUNES, J. - Os níveis de saúde no municipio de São Paulo de 1961-1967. Rev. Saúde públ., S. Paulo, 3:41-50, 1969. 